path, but this much is given in order that the practical value of these reactions and methods may be put to the test.

University of Mt. Altison College,

SACKVII Y. B.

\title{
AN ANALYTICAL INVESTIGATION OF THE HYDROLYSIS OF STARCH BY ACIDS.
}

By Geo. W. Rolfe AND Geo. Defren.

Received July 3, 1896.

CEW problems of commercial analysis have been so compli$F$ cated and so discouraging as that of the determination of the components of starch conversion products. The well-known schemes of commercial analysis of worts and similar products of the action of diastase are based on the assumption that but two simple compounds are formed from the starch-maltose and dextrin. In the case of glucose syrups and starch sugars, which are the results of acid hydrolysis, it is known that the reaction proceeds farther as dextrose is formed from the maltose and dextrin.

Musculus and Gruber decided that these reactions went on together so that except at the very beginning or final stage of hydrolysis all of these compounds must be present in solution.

The analysis of acid-converted starch products must therefore take into consideration the presence of the third compound, dextrose.

Much doubt, however, has been thrown on the accuracy of such analyses, as during the past twenty years the researches of O'Sullivan, Brown, Heron, Morris, Bondonneau, Herzfeld, Musculus, Bruckner, Fischer, and other distinguished investigators, have shown that not only the simple compounds referred to can be isolated from starch products but also many others of quite distinct optical and chemical properties. Space will not permit a review of this work, which is in many points conflicting. The recent conclusion of Lintner and Dïll is that the following compounds result from hydrolysis : ${ }^{2}$

1 Bull. Soc. Chim., 2, 30.

2 Ber. d. chem. Ges., 28, I522-153I. 

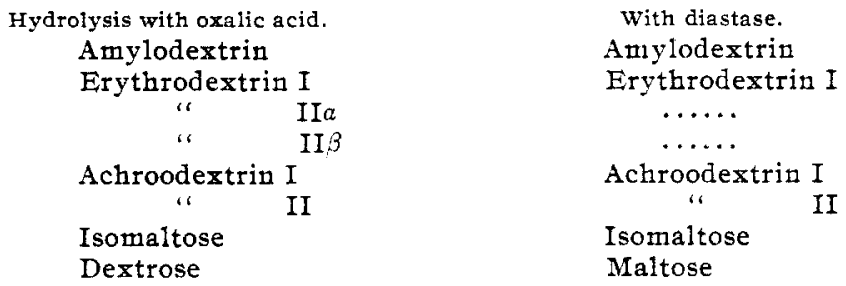

Others, as Brown and Morris, ${ }^{1}$ deny the existence of the isomaltose of Fischer and Lintner and Düll, and mention another compound, maltodextrin, an intermediate between dextrin and maltose.

In I 885 Brown and Morris ${ }^{2}$ discovered the remarkable law that at any stage of the conversion of starch by diastase, the total product, in its optical properties and relation to Fehling solution, behaved exactly as if made up of two components only, maltose and dextrin, so that it was possible by taking the rotatory power to calculate at once the cupric reducing power if the total carbohydrates were known. This law indicated that, however complicated the bodies isolated, they could be considered as existing in solution as two simple compounds, and did much to establish the validity of the principles of the usual commercial analyses of beer-worts and similar products.

The method of analysis of glucose syrups and starch sugars implies the assumption of a similar law, but the proof that this law actually exists under varying conditions of hydrolysis apparently has not been worked out. ${ }^{3}$

Our investigations have been made, first, to determine whether there was any simple constant relation between the optical rotation and the cupric reducing powers of starch products hydrolyzed under different conditions; and, secondly, whether any laws could be found affecting the three simple bodies assumed to be formed and determined by the usual methods of analysis.

Incidentally we have collected some data as to the speed of hydrolysis, influence of carbohydrates on specific gravity of

$1 J$. Chem. Soc., No. 393. Aug., 1895 .

2 Ann. Chem. (I.iebig), 23I, I3I.

3 A very complete bibliography of the original publications on the carbohydrates is in Tollen's Handbuch der Kohlenhydrate, Vo1. I, 1888 , 331-360; Vo1. II, 1895, 368-398. 
solutions, and some looking to the adoption of a more rapid and accurate method of determining cupric reducing power by Fehling solution.

The latter data are included in a separate paper. The work on specific gravities is not yet sufficiently complete for publication.

An autoclave of the usual construction was modified in the following manner: The thermometer tube was taken out and in its place was attached a specially constructed valve, by means of which liquor cooking in a beaker in the interior could be removed at any time during the progress of the experiment. This superheated liquor was prevented from vaporizing by passing through a condenser. Excessive condensation into the beaker was prevented in large part by a well fitting lead cap. The illustration sufficiently explains the apparatus.

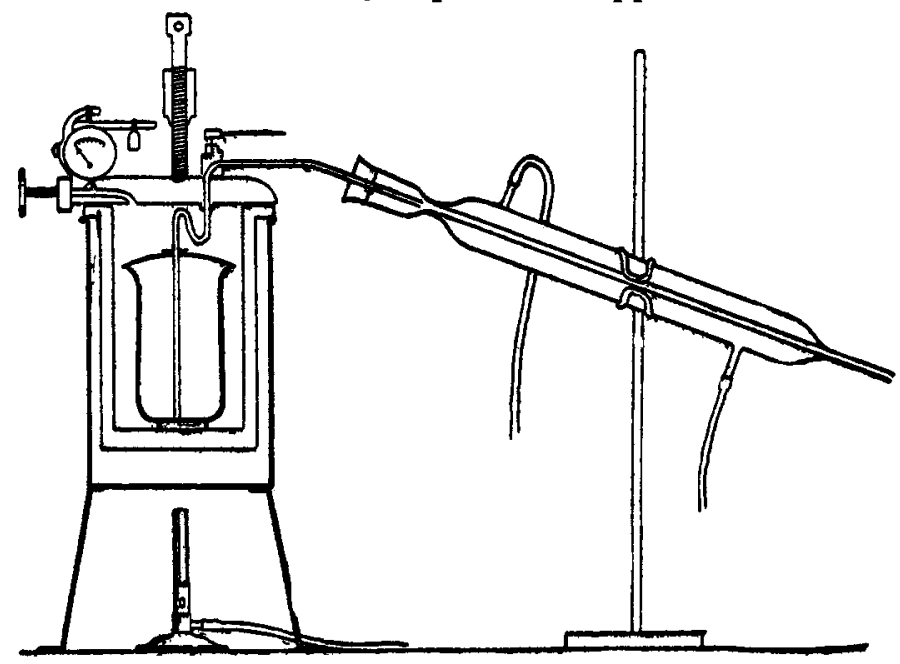

In most of the work about 100 grams of a good quality of commercial corn starch $^{1}$ was mixed with a liter of water con-

1 An analysis of this starch by the usual commercial methods gave :

Per cent.

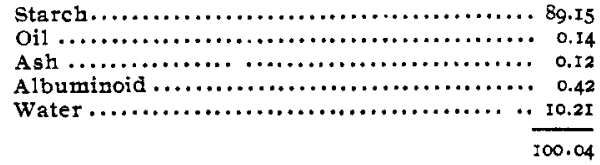


taining the hydrolyzing acid. Samples of from fifty to seventy-five cc. of the liquor were removed at different stages of the conversion and immediately shaken up with a few grams of marble dust. Two drops of tenth normal sodium hydroxide solution were then added to the sample, which was cooled and filtered. This method of nentralization, except in cases of very low converted samples, gave an absolutely clear filtrate, the filtration being exceedingly rapid, and the removal of the albuminoids being practically complete. Low-converted products often required to be heated with aluminum hydroxide before filtering.

The samples were tested as follows :

(I) For specific gravity by Westphal Balance, corrected to a temperature of $15.5^{\circ} \mathrm{C}$.

(2) Specific rotatory power $\left([\alpha]_{D}\right)$ by a Schmidt and Haensch half-shade saccharimeter.

(3) Cupric reducing power by means of Fehling solution.

Total Solids-Total solids were calculated from the specific gravity of the solution by the factor $0.003^{86}$, which was taken to represent the influence of one gram of the mixed carbohydrates in I00 cc. of solution. Corrections were made when necessary for the influence of other substances in solution, not carbohydrates. This factor 386 is practically that of Balling and Brix and has been found exact for approximately ten per cent. solutions of cane sugar, and the balance of evidence seems to be that it is correct for starch products.

We have made several determinations of this factor by drying ten $\mathrm{cc}$. of solution on rolls of dried paper at a temperature of $100-105^{\circ} \mathrm{C}$. Our results point to the constancy of this factor 386 even in solutions of low rotatory power, but are not yet complete enough to establish the value for all rotations.

Therefore, in this work we have adopted the expedient used by Brown and Morris, and others, and calculated all optical and copper reduction constants on the assumption that all three carbohydrates in solution affect the specific gravity like cane sugar when the concentration is approximately ten per cent. Even if subsequent investigations show that this view is not exactly correct, the relative values of the constant will not be appreciably affected nor the truth of the laws as set forth. 
To illustrate this method of calculation of constants we give the following from our own determinations:

Ten grams of dextrose dissolved in $100 \mathrm{cc}$. Of water gave a rotation of $30.70^{\circ}$ on the Schmidt and Haensch saccharimeter. 'This gives $[\alpha]_{\mathrm{D}}$ as 52.8 . $^{\prime}$ As the increase in specific gravity per gram of crystallized dextrose in roo cc. is $0.0038 \mathrm{I},[\alpha]_{\mathrm{D}_{3} 86}$ is 53.5 .

9.75 I grams of crystallized maltose anhydride in Ioo cc. of water gave a rotation of 76.40 . This gives an absolute specific rotatory power of 136.6. The specific gravity factor of maltose being $0.00390,[\alpha]_{D_{386}}$ is $135.2^{\circ}$. No exact figure is known for the influence of crystallized dextrin on the specific gravity of its solution. O'Sullivan gives 0.00385 , and the balance of evidence seems to favor this. Hence 195 is probably correct for $[\alpha]_{D_{386} \cdot{ }^{2}}$

In like manner the values for $K$ have been reduced to a dextrose with the factor 386 .

Specific Rotatory Power.-All readings were made as nearly as possible at a temperature of $20^{\circ} \mathrm{C}$. in $200 \mathrm{~mm}$. tubes, the mean of several readings being taken. Corrections for zero-error were made frequently, and the instrument was carefully screened by glass plates from the heat of the lamps. Comparisons were made with a Laurent polariscope to determine the value of the division in terms of angular degrees for sodium light, the accuracy of the quartz wedges having being verified previously. With standard quartz plates the usual factor 0.346 was obtained, but solutions of commercial glucose of approximately ten per cent. gave the figure 0.344 , which agrees with the recent work of Rimbach ${ }^{3}$ and other investigators. We have taken, therefore, the latter factor in our calculation.

\footnotetext{
1 Precautions against bi-rotation were taken in both examples cited.

2 Brown and Hearn: Ann. Chem, (Liebig), rg9, 190-243.

3 Ber, d. chem, Ges., 27, 2282.
} 
TABLE A.

COMPARISON OF SCHMIDT AND HAENSCH HALF-SHADE SACCHARIMETER With that of LaURent POLARISCOPE REAdiNg IN ANGULAR DEGREES.

\begin{tabular}{|c|c|c|c|c|c|c|c|}
\hline \multirow[b]{2}{*}{ Test. } & \multicolumn{3}{|c|}{$\begin{array}{l}\text { S. and } \mathrm{H} \text {. saccharimeter. } \\
\text { (Using bat-wing burner and lens.) }\end{array}$} & \multicolumn{3}{|c|}{$\begin{array}{l}\text { Laurent polariscope. } \\
\text { (Sodium flame.) }\end{array}$} & \multirow[b]{2}{*}{ Factor } \\
\hline & $\begin{array}{l}\text { Reading. } \\
(t=20-22)\end{array}$ & $\begin{array}{l}\text { Zero } \\
\text { error. }\end{array}$ & $\begin{array}{l}\text { Corrected } \\
\text { reading. }\end{array}$ & Reađing. & $\begin{array}{l}\text { Zero } \\
\text { errot. }\end{array}$ & $\begin{array}{l}\text { Corrected } \\
\text { reading. }\end{array}$ & \\
\hline uartz $A$ & A ... 62.965 & 0.300 & 62.665 & $2 I^{\circ} 40^{\prime}$ & 0 & $21.666^{\circ}$ & 0.3457 \\
\hline " & $\ldots 62.800$ & 0.150 & 62.650 & $2 \mathrm{I}^{\circ} 4 \mathrm{O}^{\prime}$ & 0 & $21.666^{\circ}$ & $0.345^{8}$ \\
\hline “ & $\ldots 62.970$ & 0.290 & 62.680 & $2 \mathrm{I}^{\circ} 40.2^{\prime}$ & $0.6^{\prime}$ & $21.660^{\circ}$ & $0.345^{8}$ \\
\hline " & $\ldots 62.836$ & 0.130 & 62.706 & $2 \mathrm{I}^{\circ} 40.7^{\prime}$ & $c .6^{\prime}$ & $21.666^{\circ}$ & 0.3455 \\
\hline lucose & A.. 77.510 & 0.277 & 77.233 & $26^{\circ} 35^{\prime}$ & 0 & $26.582^{\circ}$ & 0.3442 \\
\hline " & B $\ldots 7^{6.355}$ & 0.150 & 76.205 & $26^{\circ} \mathrm{I} 5 \cdot 3^{\prime}$ & $\circ$ & $26.254^{\circ}$ & 0.3445 \\
\hline " & B $\ldots 76.355$ & 0.150 & 76.205 & $26^{\circ} \mathrm{I} 4^{\prime}$ & 0 & $26.233^{\circ}$ & $0.344=$ \\
\hline “" & C... $7^{6.535}$ & 0.150 & 76.385 & $26^{\circ} \mathrm{I} 8^{\prime}$ & $\circ$ & 26.3 & 0.3443 \\
\hline$"$ & $\begin{array}{l}D \cdots 76.110 \\
(t=25)\end{array}$ & 0.130 & 75.980 & $26^{\circ}$ I0. $3^{\prime}$ & $0.6^{\prime}$ & $26.162^{\circ}$ & 0.3443 \\
\hline ducts & $\left.\begin{array}{l}z- \\
\text { h } \\
s\end{array}\right\} \begin{array}{l}\text { E. } 92.73^{l} \\
\text { F. } 24.84\end{array}$ & $\begin{array}{l}\infty \\
\infty\end{array}$ & $\begin{array}{l}92.73 \\
24.84\end{array}$ & $\begin{array}{l}31^{\circ} 5^{6^{\prime}} \\
8^{\circ} \\
3^{\prime} 2^{\prime}\end{array}$ & $\begin{array}{l}-I^{\prime} \\
-I^{\prime}\end{array}$ & $\begin{array}{l}3 \mathrm{I} .95^{\circ} \\
8.55^{\circ}\end{array}$ & $\begin{array}{l}0.3445 \\
0.344^{2}\end{array}$ \\
\hline
\end{tabular}

Cupric Reducing Power.-Our method is practically that of O'Sullivan, first published in 1876 . The copper is weighed as the oxide. We have found this method exact and rapid. An analytical investigation of this process has been made by one of us and given in detail in a separate paper.

Plotted Results.-To show the relationship of the copper-reducing power, and the specific rotatory power of the products formed during the progress of the hydrolysis of the starch, we have plotted our results, taking as abscissae the decreasing values of the rotatory power, from the amylodextrin stage $\left(195^{\circ}\right)$ to that of dextrose $\left([\alpha]_{\mathrm{D}_{366}}=53.5^{\circ}\right)$, and as ordinates the cupric reducing power $\left(\mathrm{K}_{386}\right)$ taking that of an equivalent weight of dextrose as 10o. $^{2} \quad$ [See Plate A.]

1 Using Welsbach burner.

2Data given in Table $B$. 


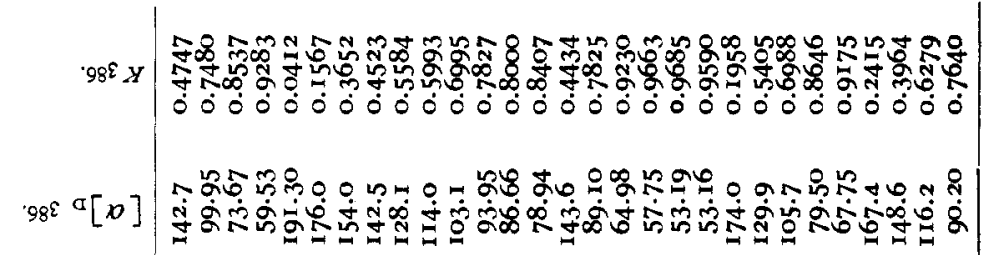

.əpixo jaddos

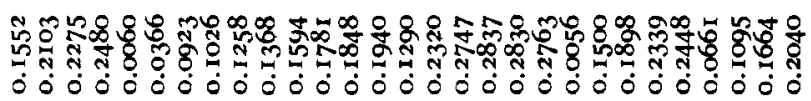

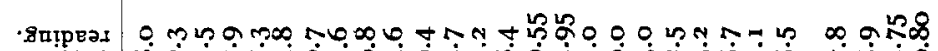

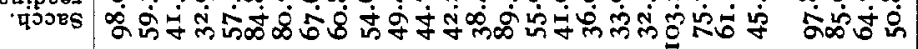

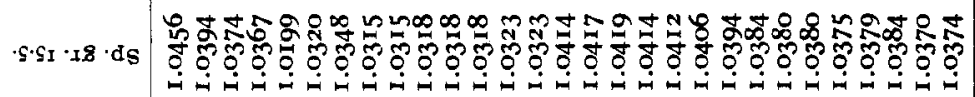
.20 มәнем \& 8

8

8 . วงนnotay $\varrho$

8

8

8

$\int=0 \quad=0$

돈

$=$

$\pm$

pr!x

U

式

$\ddot{3}$

$\Xi$

苩

ว.nnssasd opioudsomit

ง

ง

e

N

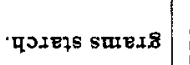

$\stackrel{9}{-1}$

$\stackrel{ }{g}$

$\stackrel{2}{2}$

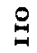

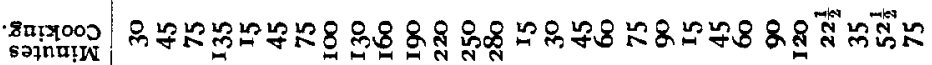

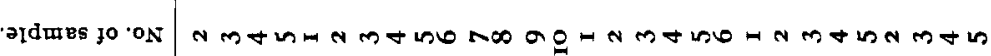
ing $\$$ 


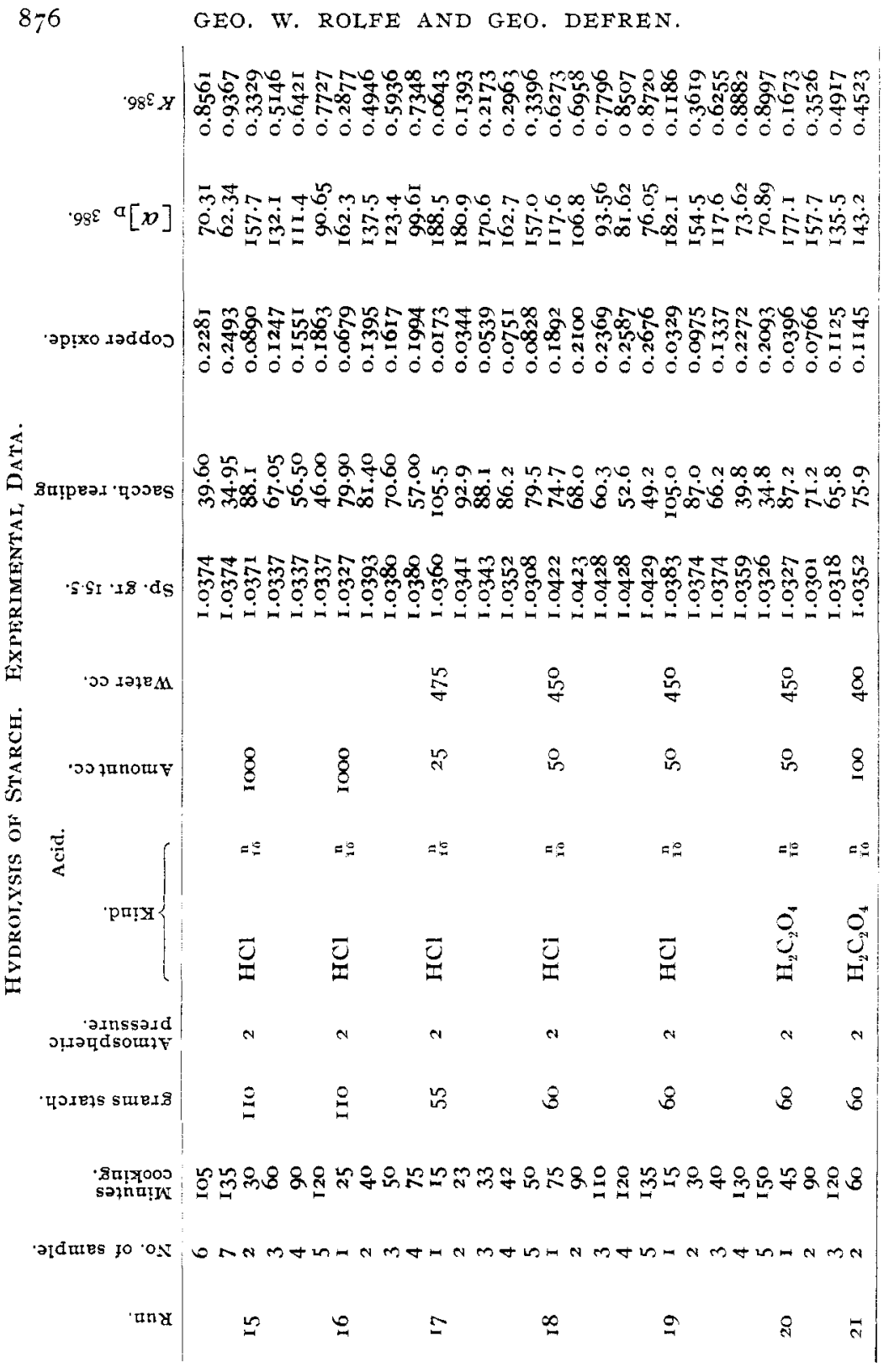


HYDROLYSIS OF STARCH BY ACIDS.

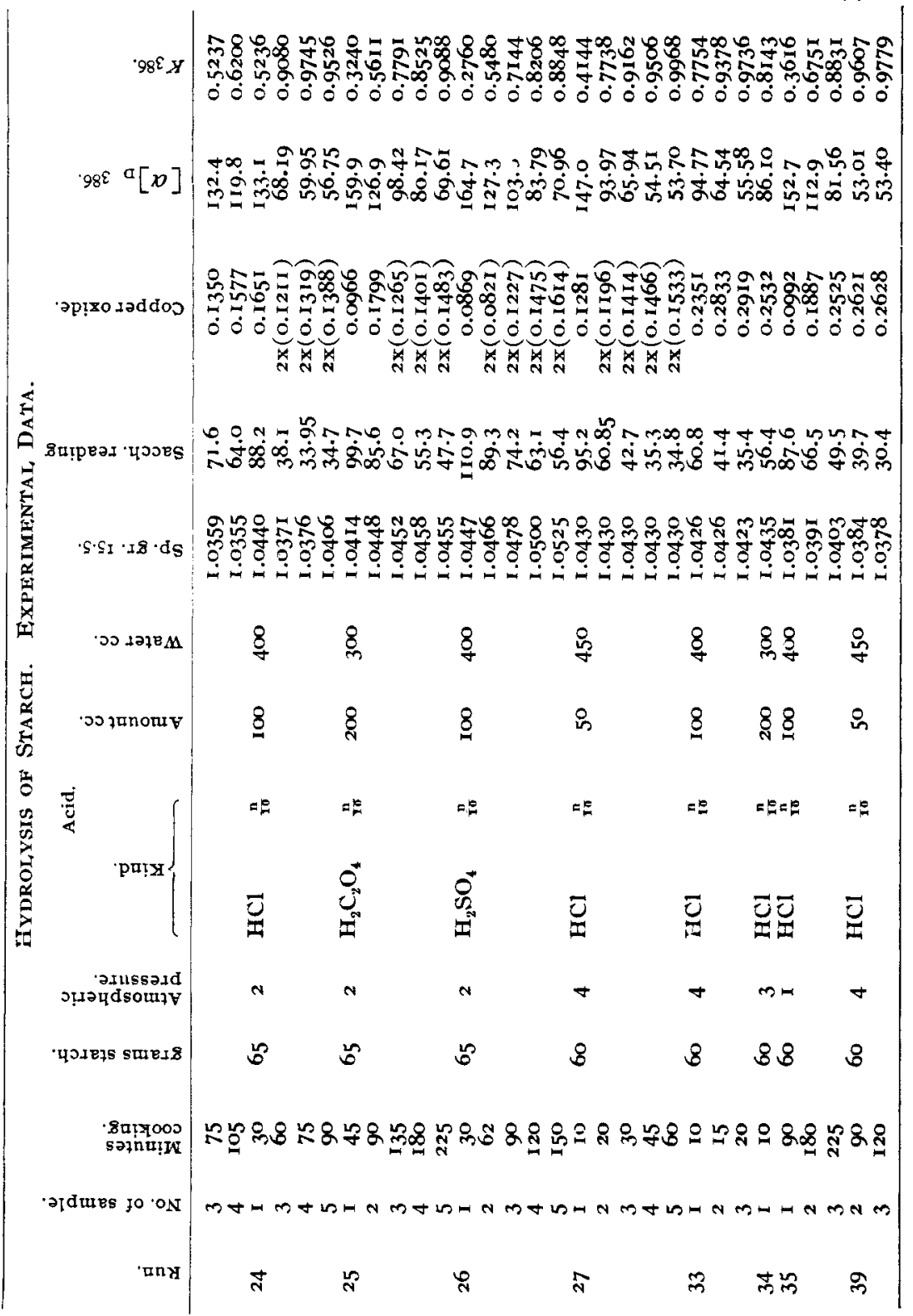



878
GEO. W. ROLFE AND GEO. DEFREN.

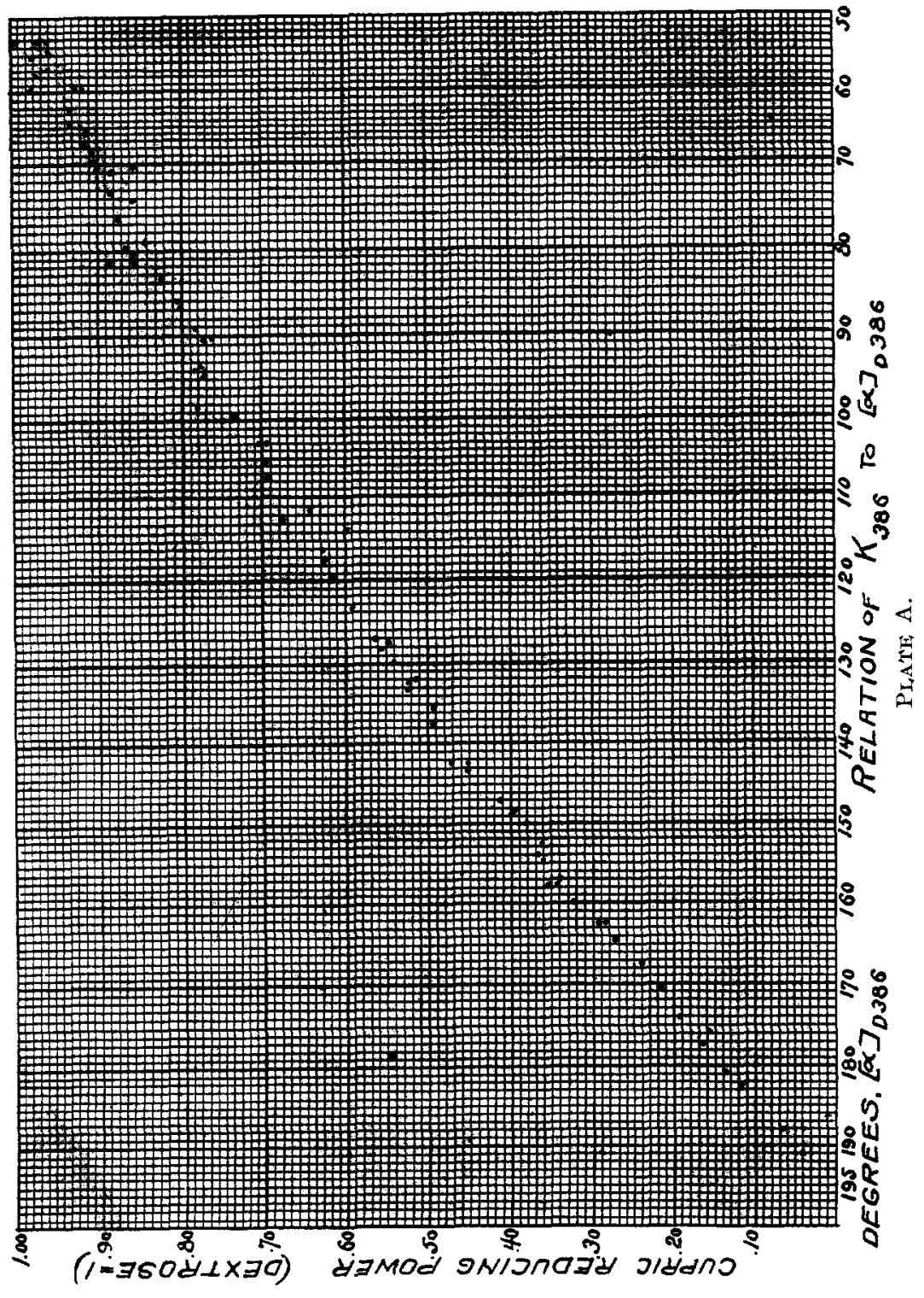


The results point to the remarkable fact that the cupric reducing power of the total product bears a constant relation to the specific rotatory power, even when the starch is hydrolyzed under widely varying conditions. Hence, given the one, the value of the other can be calculated. To a rotation of about $90^{\circ}$, the plotted results outline with extraordinary exactness the arc of a circle, the equation of which is

$$
x^{2}+y^{2}+468 x-646 y+1580=0,
$$

which exactly intercepts the "zero" and "hundred" points at I 95 and 53.5, respectively. The upper part of the curve is not so well defined, the results showing more discrepancy at the high conversion stages. This may be due to some decomposition and the formation of "reversion" products as stated by Wohl, ${ }^{1}$ Maercker, Ost, and others. Wohl's figures show the maximum amount of dextrose possible to be 92.7 per cent. of the theoretical quantity. Others give ninety-six to ninety-seven per cent., the missing dextrose being supposed to be converted into dextrin-like bodies identical with those variously described as "gallisin," "isomaltose," etc. We have experimented but little along this line, having made but one hydrolysis with this special object, using $\frac{\mathrm{N}}{\mathrm{T}^{0} \delta}$ hydrochloric acid at four atmospheres pressure, with the following results :

\begin{tabular}{|c|c|c|}
\hline \multicolumn{2}{|c|}{$\begin{array}{l}\text { Time of cooking. } \\
60 \text { minutes }\end{array}$} & $\begin{array}{l}\lfloor\alpha\rfloor_{\mathrm{D}} \cdot \\
55.24\end{array}$ \\
\hline 90 & " & 53.09 \\
\hline 120 & $"$ & 53.40 \\
\hline 150 & " & 54.42 \\
\hline
\end{tabular}

While several of our own results at the low rotations show a cupric reducing power of only about ninety-six per cent. of that of pure dextrose, we do not think that we are justified in arriving at any definite conclusion with the data at hand.

That the solutions begin to color considerably at rotations beyond $90^{\circ}$ is, moreover, a strong indication of such decomposition. On the other hand, this accounts for much of the discrepancy of the plot at this part of the curve, as it is exceedingly difficult to get accurate readings on the saccharimeter of these highly colored solutions. Obviously, too, slight errors in the

1 Ber. d. chem. Ges., 23, 2101. 
readings affect the calculations of the rotatory power the most at these lowest rotations.

Quite as noteworthy are the curves ${ }^{1}$ plotted by taking the values of maltose, dextrin, and dextrose as computed for every

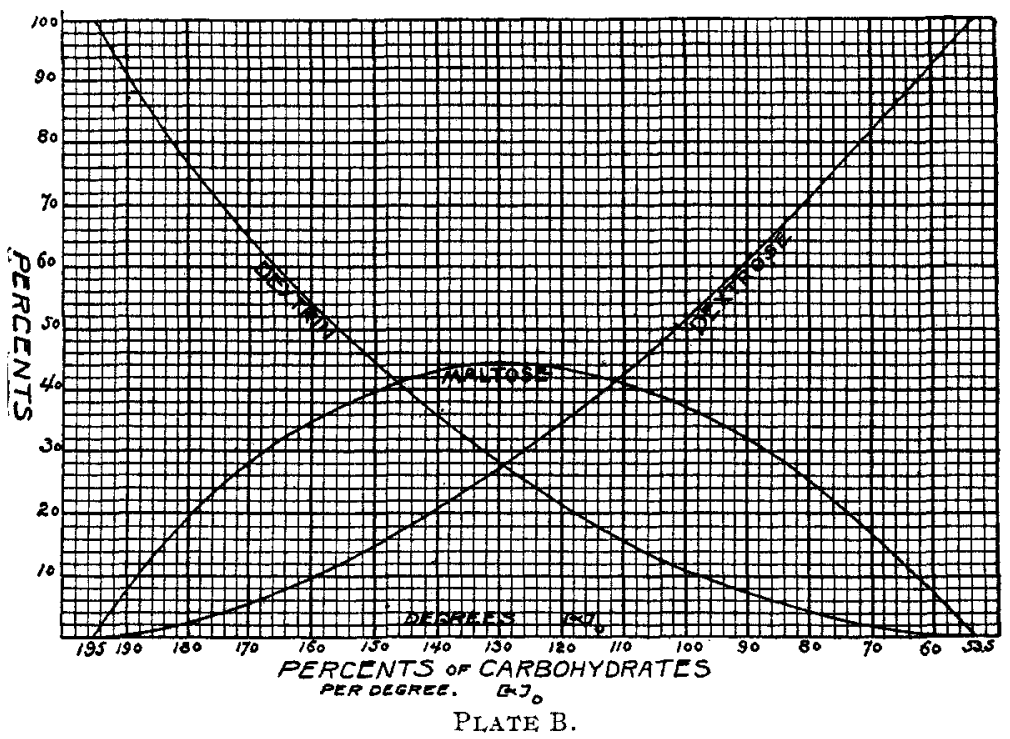

five degrees of rotation from the values of $K$, as given by this curve.

In this work we have figured constants for solids estimated from the specific gravities of solutions by the factor, 386 , and calculated percentages by the well-known equations:

$$
\begin{aligned}
& g+m+d=1.00 \\
& g+0.6 \mathrm{I} m=K \\
& 195^{d}+\mathrm{I} 35.2 m+53.5 g=\alpha
\end{aligned}
$$

Where $g$ is per cent. dextrose, $m$ is per cent. maltose, and $d$ is per cent. dextrin.

$$
\text { Hence, } m=\frac{d+\mathrm{I} 4 \mathrm{I} .5 K-\mathrm{I} 95}{27.82}
$$

1 See plate $B$. 
Examining these curves we see that the dextrin starting from the maximum of 100 per cent. gradually falls to zero near the rotation corresponding to dextrose, while the maltose gradually rises, reaches a maximum percentage of 44.1 at about $129^{\circ}$ rotation, corresponding to the usual state of conversion of commercial glucose, and then falls, disappearing at $53.5^{\circ}$. The dextrose, on the contrary, steadily mounts to roo per cent. It will be noted, too, that at the point of maximum maltose the dextrin and dextrose, as shown by the intersection of the curves, are present in equal quantity.

Tests with phenylhydrazin acetate show the presence of the dextrose distinctly at about $185^{\circ}$, and we had hoped to prove the gradual rise of the dextrose percentage by means of the dextrosazon. While copious precipitates of this beautiful compound were obtained, any attempt of ours to isolate it in anything like quantitative amounts proved a failure, even in solutions containing a known amount of pure dextrose. We hope to take this up more fully in a later investigation.

We have also calculated a table (Table C) from the curves giving the value of maltose, dextrose, and dextrin within onetenth per cent. for successive stages of acid hydrolysis represented by each degree of rotation between 195 and 53.5. This table, calculated for the factor 386 , makes no allowance for possible decomposition of high-converted products.

TABLE C.

Calculated Values of Cupric Reducing Powers and Parts of MalTOSE, DEXTROSE AND DEXTRIN PER UNIT OF CARBOHYDRATE FOR

EACH DEgREE OF Rotation OF a NoRMaliy HydRoLYZED STARCH SOlution.

$\begin{array}{cllll}{[\alpha]_{\mathrm{D}^{386^{\circ}}}^{20}} & K_{888^{\circ}} & M_{\mathrm{8B8}} & g_{380^{\circ}} & d_{380^{\circ}} \\ 195 & 0.000 & 0.000 & 0.000 & 1.000 \\ 194 & 0.01 \mathrm{I} & 0.017 & 0.00 \mathrm{I} & 0.982 \\ 193 & 0.022 & 0.033 & 0.001 & 0.966 \\ 192 & 0.032 & 0.048 & 0.002 & 0.950 \\ 191 & 0.041 & 0.063 & 0.002 & 0.935 \\ 190 & 0.051 & 0.079 & 0.003 & 0.918 \\ 189 & 0.061 & 0.094 & 0.004 & 0.902 \\ 188 & 0.071 & 0.110 & 0.005 & 0.885 \\ 187 & 0.081 & 0.123 & 0.007 & 0.870\end{array}$




\begin{tabular}{|c|c|c|c|c|}
\hline$[\alpha]_{D_{98} 0^{\circ}}$ & $K_{38 \mathrm{~B}}$ & $M_{38 \theta}$. & $g_{38 B}$ & $d_{986}$ \\
\hline I86 & 0.090 & 0.135 & 0.009 & 0.856 \\
\hline 185 & 0.100 & 0.147 & 0.010 & 0.843 \\
\hline I 84 & 0.109 & 0.160 & 0.013 & 0.827 \\
\hline $\mathrm{r} 83$ & 0.118 & 0.171 & 0.016 & $0.8 \mathrm{I} 3$ \\
\hline 182 & 0.127 & 0.182 & 0.019 & 0.799 \\
\hline $18 \mathrm{r}$ & 0.137 & 0.192 & 0.022 & 0.786 \\
\hline I8o & 0.146 & 0.203 & 0.025 & 0.772 \\
\hline I 79 & 0.155 & 0.212 & 0.028 & 0.760 \\
\hline I 78 & 0.164 & 0.222 & 0.031 & 0.747 \\
\hline I77 & O.I73 & $0.23 \mathrm{I}$ & 0.034 & 0.735 \\
\hline $17^{6}$ & 0.182 & 0.240 & 0.037 & 0.723 \\
\hline I 75 & 0.191 & $0.25^{\circ}$ & 0.040 & 0.710 \\
\hline I 74 & 0.199 & 0.257 & 0.043 & 0.700 \\
\hline I 73 & 0.207 & 0.265 & 0.047 & 0.688 \\
\hline 172 & 0.216 & 0.273 & $0.05^{\circ}$ & 0.677 \\
\hline 171 & 0.224 & 0.280 & 0.054 & 0.666 \\
\hline 170 & 0.233 & 0.287 & $0.05^{8}$ & 0.655 \\
\hline 169 & 0.242 & 0.294 & 0.062 & 0.644 \\
\hline 168 & $0.25 \mathrm{I}$ & 0.301 & 0.066 & 0.633 \\
\hline 167 & 0.259 & 0.307 & 0.071 & 0.622 \\
\hline I 66 & 0.267 & 0.314 & 0.075 & $0.6 \mathrm{II}$ \\
\hline 165 & 0.275 & 0.320 & 0.080 & 0.600 \\
\hline 164 & 0.283 & 0.326 & 0.084 & 0.590 \\
\hline $16_{3}$ & 0.292 & 0.332 & 0.089 & 0.579 \\
\hline 162 & 0.300 & $0.33^{8}$ & 0.093 & 0.569 \\
\hline I6I & 0.308 & 0.344 & 0.098 & $0.55^{8}$ \\
\hline 160 & 0.316 & 0.349 & 0.103 & 0.548 \\
\hline I 59 & 0.324 & 0.356 & 0.107 & 0.537 \\
\hline 58 & 0.332 & 0.362 & O.III & 0.527 \\
\hline I 57 & 0.340 & 0.369 & O.II5 & 0.516 \\
\hline I 56 & 0.348 & 0.373 & $0.12 \mathrm{I}$ & 0.506 \\
\hline I55 & 0.356 & 0.378 & 0.126 & 0.496 \\
\hline I 54 & 0.365 & $0.3^{8} 3$ & 0.130 & 0.487 \\
\hline r53 & 0.373 & $0.3^{88}$ & o.I35 & 0.477 \\
\hline 152 & $0.3^{8} \mathrm{I}$ & 0.392 & $0.14 I$ & 0.467 \\
\hline $15 I$ & $0.3^{89}$ & 0.397 & o. 146 & 0.457 \\
\hline I5O & 0.397 & $0.4 \mathrm{OI}$ & o.I 53 & 0.446 \\
\hline 149 & 0.404 & 0.405 & O.I 57 & $0.43^{8}$ \\
\hline I 48 & $0.4 \mathrm{I} 2$ & 0.408 & $0.16_{3}$ & 0.429 \\
\hline I 47 & 0.419 & 0.412 & 0.164 & 0.420 \\
\hline 146 & 0.427 & $0.4 \mathrm{I} 5$ & 0.174 & $0.4 I I$ \\
\hline I45 & 0.435 & $0.4 I 5$ & 0.182 & 0.403 \\
\hline 144 & 0.442 & 0.421 & o. I 86 & 0.393 \\
\hline I 43 & $0.45^{\circ}$ & 0.423 & 0.192 & $0.3^{8} 5$ \\
\hline
\end{tabular}


HYDROLYSIS OF STARCH BY ACIDS.

\begin{tabular}{|c|c|c|c|c|}
\hline$[\alpha]_{D_{380}^{20}}^{20}$ & $K_{388}$ & $M_{386}$. & $g_{380^{\circ}}$ & $d_{938}$ \\
\hline I 42 & 0.458 & 0.425 & 0.199 & 0.376 \\
\hline I 41 & 0.465 & 0.427 & 0.205 & 0.368 \\
\hline I 40 & 0.473 & 0.428 & 0.212 & 0.360 \\
\hline I39 & $0.48 \mathrm{I}$ & 0.431 & 0.217 & $0.35^{2}$ \\
\hline I 38 & 0.488 & 0.432 & 0.224 & 0.344 \\
\hline I37 & 0.496 & 0.434 & $0.23 I$ & 0.335 \\
\hline 136 & 0.503 & 0.436 & 0.237 & 0.327 \\
\hline I 35 & 0.510 & 0.437 & 0.243 & 0.320 \\
\hline I34 & 0.517 & $0.43^{8}$ & 0.249 & $0.3 \mathrm{I} 3$ \\
\hline 133 & 0.524 & 0.439 & 0.256 & 0.305 \\
\hline 132 & $0.53 \mathrm{I}$ & 0.439 & 0.263 & 0.298 \\
\hline $13 I$ & 0.538 & 0.440 & 0.270 & 0.290 \\
\hline 130 & 0.546 & 0.440 & 0.277 & 0.283 \\
\hline 129 & 0.553 & $0.44 \mathrm{I}$ & 0.284 & 0.275 \\
\hline 128 & 0.560 & $0.44 \mathrm{I}$ & $0.29 \mathrm{I}$ & 0.268 \\
\hline 127 & 0.567 & 0.440 & 0.298 & 0.262 \\
\hline I 26 & 0.574 & 0.440 & 0.305 & 0.255 \\
\hline I 25 & 0.580 & 0.439 & $0.3 I_{3}$ & 0.248 \\
\hline I 24 & $0.5^{88}$ & $0.43^{8}$ & 0.320 & 0.242 \\
\hline 123 & 0.595 & $0.43^{8}$ & 0.327 & 0.235 \\
\hline 122 & 0.602 & 0.437 & 0.335 & 0.228 \\
\hline I 2 I & 0.608 & $0.43^{6}$ & 0.343 & $0.22 \mathrm{I}$ \\
\hline 120 & 0.614 & 0.435 & $0.35^{\circ}$ & 0.215 \\
\hline II & $0.62 \mathrm{I}$ & 0.433 & $0.35^{8}$ & 0.209 \\
\hline I I 8 & 0.628 & $0.43 I$ & 0.366 & 0.203 \\
\hline II7 & 0.635 & 0.429 & 0.374 & 0. 197 \\
\hline I I 6 & 0.642 & 0.428 & $0.38 \mathrm{I}$ & o.rgI \\
\hline 115 & 0.649 & 0.425 & 0.390 & 0.185 \\
\hline II4 & 0.656 & 0.422 & 0.398 & 0.180 \\
\hline II 3 & 0.663 & 0.420 & 0.408 & 0.174 \\
\hline II 2 & 0.669 & 0.417 & 0.414 & 0.169 \\
\hline I I I & 0.675 & $0.4 \mathrm{I} 4$ & 0.423 & 0.164 \\
\hline IIO & $0.68 I$ & 0.408 & 0.432 & 0.160 \\
\hline IO9 & 0.687 & 0.407 & 0.439 & 0.154 \\
\hline 108 & 0.694 & 0.403 & 0.448 & 0.149 \\
\hline 107 & 0.700 & 0.400 & $0.45^{6}$ & 0.144 \\
\hline 106 & 0.707 & 0.396 & 0.465 & 0.139 \\
\hline 105 & 0.713 & 0.392 & 0.474 & o. I34 \\
\hline 104 & و11 0.7 & $0.3^{87}$ & 0.483 & 0.130 \\
\hline 103 & 0.725 & $0.3^{8} 3$ & 0.492 & 0.125 \\
\hline 102 & 0.732 & 0.379 & 0.500 & $0.12 \mathrm{I}$ \\
\hline IOI & $0.73^{8}$ & 0.375 & 0.508 & 0.117 \\
\hline 100 & 0.744 & $0.37^{\circ}$ & $0.5 \mathrm{r} 8$ & O.II2 \\
\hline 99 & $0.75^{\circ}$ & 0.366 & 0.527 & 0.107 \\
\hline
\end{tabular}




\begin{tabular}{|c|c|c|c|c|}
\hline$\alpha]_{\mathbb{D}_{380^{\circ}}}^{20}$ & $K_{386}$. & $M_{380^{\circ}}$ & $g_{3 \in 6}$ & $d_{388^{\circ}}$ \\
\hline 98 & 0.757 & $0.36 \mathrm{I}$ & 0.537 & 0.102 \\
\hline 97 & 0.763 & 0.356 & 0.546 & 0.098 \\
\hline 96 & 0.769 & 0.350 & $0.55^{6}$ & 0.094 \\
\hline 95 & 0.775 & 0.345 & $0.5^{6} 5$ & 0.090 \\
\hline 94 & $0.78 \mathrm{I}$ & $0.34 \mathrm{I}$ & 0.574 & 0.085 \\
\hline 93 & 0.787 & $0.33^{6}$ & $0.5^{8} 3$ & $0.08 \mathrm{I}$ \\
\hline 92 & 0.793 & $0.33 I$ & 0.592 & 0.077 \\
\hline $9 \mathrm{I}$ & 0.799 & 0.326 & 0.601 & 0.073 \\
\hline 90 & 0.805 & 0.320 & 0.6 Io & 0.070 \\
\hline 89 & 0.810 & 0.314 & 0.620 & 0.066 \\
\hline 88 & 0.816 & 0.308 & 0.629 & 0.063 \\
\hline 87 & 0.822 & 0.302 & 0.638 & 0.060 \\
\hline 86 & 0.828 & 0.295 & 0.649 & 0.056 \\
\hline 85 & 0.834 & 0.288 & $0.65^{8}$ & 0.054 \\
\hline 84 & 0.839 & 0.282 & 0.667 & 0.051 \\
\hline 83 & 0.844 & 0.275 & 0.677 & 0.048 \\
\hline 82 & 0.850 & 0.267 & 0.688 & 0.045 \\
\hline $8 \mathrm{I}$ & $0.85^{6}$ & 0.259 & 0.698 & 0.043 \\
\hline 80 & 0.862 & $0.25 \mathrm{I}$ & 0.709 & 0.040 \\
\hline 79 & 0.867 & 0.243 & 0.719 & 0.038 \\
\hline 78 & 0.872 & 0.234 & 0.730 & 0.036 \\
\hline 77 & 0.878 & 0.225 & $0.74 \mathrm{I}$ & 0.034 \\
\hline 76 & 0.884 & 0.217 & $0.75^{I}$ & 0.032 \\
\hline 75 & 0.889 & 0.208 & 0.762 & 0.030 \\
\hline 74 & 0.895 & 0.200 & 0.772 & 0.028 \\
\hline 73 & 0.901 & o.I9I & 0.783 & 0.026 \\
\hline 72 & 0.906 & 0.182 & 0.794 & 0.024 \\
\hline $7 I$ & 0.911 & 0.173 & 0.805 & 0.022 \\
\hline 70 & 0.916 & 0.163 & 0.817 & 0.020 \\
\hline 69 & 0.921 & o.I 53 & 0.828 & 0.019 \\
\hline 68 & 0.926 & 0.143 & 0.839 & 0.018 \\
\hline 67 & 0.932 & o. I 34 & 0.850 & 0.016 \\
\hline 66 & 0.937 & 0.125 & $0.86 \mathrm{I}$ & 0.014 \\
\hline 65 & 0.942 & O.II5 & 0.872 & 0.013 \\
\hline 64 & 0.947 & 0.105 & $0.88_{3}$ & 0.012 \\
\hline 63 & 0.952 & 0.095 & 0.895 & 0.010 \\
\hline 62 & 0.957 & 0.085 & 0.906 & 0.009 \\
\hline $6 I$ & 0.962 & 0.075 & 0.917 & 0.008 \\
\hline 60 & 0.967 & 0.065 & 0.927 & 0.008 \\
\hline 59 & $0.97^{2}$ & 0.055 & 0.938 & 0.007 \\
\hline $5^{8}$ & 0.977 & 0.045 & 0.949 & 0.006 \\
\hline 57 & 0.982 & 0.035 & 0.960 & 0.005 \\
\hline 56 & 0.987 & 0.025 & $0.97 \mathrm{I}$ & 0.004 \\
\hline 55 & 0.992 & 0.015 & 0.982 & 0.003 \\
\hline 54 & 0.997 & 0.005 & 0.993 & 0.002 \\
\hline $53 \cdot 5$ & 1.000 & 0.000 & I. 000 & 0.000 \\
\hline
\end{tabular}


It would seem obvious that we are now prepared to determine whether a sample of glucose is a product of one hydrolysis or is a mixture of two separately converted products, by comparison of the actual analytical results with those calculated from the rotatory power.

For testing this method we have made a few analyses of commercial glucoses obtained in open market.

In the manufacture of glucose syrup all the starch is not hydrolyzed under strictly the same conditions, as the factory practice is to pump the starch into the converter, which is under steam pressure and already contains the hydrolyzing acid. As the filling of a converter takes about one-third of the total time of cooking, it is clear that there is a radical difference in the time of hydrolysis of different portions of starch. Nevertheless, we have found that samples known to have been made under these conditions conform to the laws of our curve, and the evidence seems strong that those which depart widely from these conditions are mechanical mixtures.

The following determinations of four samples of commercial glucose giving the cupric reducing power as found and as calculated for the corresponding rotation will illustrate the method:
I. C. Pape Co. (J) ..... I3 I I.I
$K_{386}$ (obtained). $K_{386}$ (calculated).
II. C. Pope Co. (M) .... I25.4
0.566
0.578
0.537
III. Rockford Co ....... I I I.9
0.454
0.578
IV. Chicago Co....... I 37.2
0.505
0.457
0.495

Evidently II and III are normally hydrolyzed. IV is possibly a mixture, while $I$ is undoubtedly so. As this latter is a sample of jelly goods which in factory practice are often made by mixing two lots, our conclusion is strengthened.

From the results as a whole we have concluded that the evidence is strong, ( $\mathrm{I}$ ) that in any homogeneous acid-converted starch product, irrespective of the conditions of hydrolysis, the specific rotatory power always represents the same chemical composition.

(2) That but three simple carbohydrates, ${ }^{1}$ possible in molecular aggregates, exist in the solution of a starch product hydrolyzed by acids.

1 Leaving out of consideration the possible small amounts of products formed by reversion. 
DETERMINATION OF THE CONVERSION OF COMMERCIAL, GLUCOSE.

In the manufacture of glucose it is obviously essential to have a rapid means of determining the degree of conversion of the starch during the cooking process. The usual factory practice is to control the conversion by means of iodine color tests. These tests are usually made by adding a definite number of drops of standard iodine solution to a test-tube of the cooled glucose liquor. The tint at which the conversion is considered complete varies in general practice from that corresponding to $[\alpha]_{\mathrm{D}}=\mathrm{I} 28$ to $[\alpha]_{\mathrm{D}}=\mathrm{I} 35$, the variation being even greater in some cases, depending on the ideas of the manufacturer and the grade of goods desired.

By daily practice workmen become quite expert in making these iodine tints, which are usually carried out by crude methods and read off without comparison with any standard. Nevertheless, the product, when examined by more refined laboratory processes, shows wide variations from day to day, which does not appear surprising when we examine into the errors of such color tests.

Assuming that the test is carried out under uniform conditions of concentration and proportion of reagent to liquor to be tested, which is by no means always the case, the other conditions affecting the color are (I) temperature, (2) turbidity, and (3) illumination.

Uniform temperature can be obtained easily by some simple cooling device as a stream of running water.

The acid converter liquors are always turbid when tested, as filtration in this rapid testing is impracticable. The turbidity, however, is fairly constant. It is the third condition, that of illumination, which is constantly variable and which gives rise to the greatest error. This source of error can be largely eliminated by the use of a comparison standard, prepared of the same volume as that used in the color test and hermetically sealed in a glass tube of the standard size used in testing. Mixtures of solutions of iron salts with finely pulverized glass giving the requisite turbidity when shaken, can be easily made to exactly match the iodine tint, and will preserve their intensity indef- 
nitely. When properly adjusted by means of polariscopic tests such standards have served well to fix the point of conversion within narrow limits and have done much to insure a uniform product.

It is of course important that these should be in the hands of the chemist or superintendent of the works, a much more exact means of testing the degree of conversion. This is most naturally accomplished by determining the specific rotatory power.

We have arranged a table for quickly calculating specific rotatory power, and found it so useful that we venture to publish it. The following simple calculation will sufficiently explain the principles on which the table has been worked out:

TABLE D.

TABLE FOR DETERMINING SPECIFIC ROTATORY POWER OF SOLUTIONS OF $7.50^{\circ}-10^{\circ}$ BRIX BY READING OF VENTZKE SACCHARIMETER.

\begin{tabular}{|c|c|c|c|c|c|c|c|}
\hline Brix. & Sp. gr. & $\begin{array}{l}W=\text { gram } \\
\text { per Io0 cc. }\end{array}$ & $\log \frac{I 7.20}{W}$ & Brix. & Sp. gr. & $\begin{array}{l}W=\text { gram } \\
\text { per } 100 \mathrm{cc} .\end{array}$ & $\log \left(\frac{17.20}{W}\right)$ \\
\hline $7 \cdot 50$ & 1.0298 & 7.724 & 0.3477 & 8.80 & I.0352 & g.IIO & 0.2760 \\
\hline 7.55 & 1.0300 & 7.777 & 0.3447 & 8.85 & I. 0354 & 9.163 & 0.2735 \\
\hline 7.60 & 1.0302 & 7.829 & 0.3418 & 8.90 & $1.035^{6}$ & 9.217 & 0.2709 \\
\hline 7.65 & 1.0304 & 7.883 & 0.3388 & 8.95 & $1.035^{8}$ & 9,270 & 0.2684 \\
\hline 7.70 & 1.0306 & 7.936 & 0.3359 & 9.00 & 1.0360 & 9.324 & 0.2657 \\
\hline 7.75 & I. 0308 & 7.989 & 0.3330 & 9.05 & I. 0362 & $9 \cdot 37^{8}$ & 0.2634 \\
\hline 7.80 & 1.0320 & 8.042 & 0,3301 & 9.10 & 1.0364 & 9.430 & 0.2610 \\
\hline 7.85 & 1.0312 & 8.096 & 0.3272 & 9.15 & 1.0366 & 9.484 & 0.2585 \\
\hline 7.90 & I.0315 & 8. 149 & 0.3244 & 9.20 & $\mathrm{I} .0368$ & 9.538 & 0.2560 \\
\hline 7.95 & I.03I7 & 8.202 & 0.3216 & 9.25 & 1.0370 & $9 \cdot 592$ & 0.2536 \\
\hline 8.00 & 1.0319 & 8.255 & 0.3187 & 9.30 & 1.0372 & 9.646 & 0.2510 \\
\hline 8.05 & $\mathrm{I} .032 \mathrm{I}$ & 8.308 & 0.3160 & 9.35 & I. 0374 & 9.690 & 0.2488 \\
\hline 8.10 & 1.0323 & $8.36 I$ & 0.3532 & $9.4^{\circ}$ & 1.0376 & 9.753 & 0.2464 \\
\hline 8.15 & 1.0325 & $0.4 \mathrm{I} 5$ & $0.3 \mathrm{IO} 4$ & 9.45 & 1.0378 & 9.807 & $0.244^{\circ}$ \\
\hline 8.20 & 1.0327 & 8.468 & 0.3077 & $9.5^{\circ}$ & $\mathrm{I} .038 \mathrm{I}$ & 9.862 & 0.2415 \\
\hline 8.25 & 1.0329 & 8.522 & 0.3050 & 9.55 & 1.0383 & 9.916 & $0.239 \mathrm{I}$ \\
\hline 8.30 & I. $033=$ & 8.575 & 0.3022 & 9.60 & I. .0385 & 9.970 & 0.2368 \\
\hline 8.35 & I. 0333 & 8.629 & 0.2995 & 9.65 & 1.0387 & 10.023 & 0.2346 \\
\hline 8.40 & 1.0335 & 8.682 & 0.2969 & 9.70 & 1.0389 & 10.077 & 0.2323 \\
\hline 8.45 & 1.0337 & 8.735 & 0.2943 & 9.75 & I.039I & 10.130 & 0.2300 \\
\hline 8.50 & I.0339 & 8.788 & 0.2916 & 9.80 & I. 0393 & 10.185 & 0.2277 \\
\hline 8.55 & I.034 I & 8.842 & 0.2889 & 9.85 & 1.0395 & 10.239 & 0.2252 \\
\hline 8.60 & I. 0343 & 8.895 & 0.2864 & 9.90 & 1.0397 & 10.293 & $0.223 I$ \\
\hline 8.65 & I. 0345 & 8.949 & 0.2838 & 9.95 & 1.0399 & 10.347 & 0.2207 \\
\hline 8.70 & 1.0347 & 9.002 & $0.28 \mathrm{I} 2$ & 10.00 & 1.0401 & 10.401 & 0.2185 \\
\hline 8.75 & I. $035^{\circ}$ & 9.056 & 0.2786 & & & & \\
\hline
\end{tabular}

Taking the usual formula for the specific rotatory power, $\alpha=\frac{a v}{l w}$, where $a$ is the angle of rotation of the solution of $w$ 
gram of the active substance in $v \mathrm{cc}$. of water observed through a column $l$ decimeters long. If we make $a=\alpha$ it is plain $w$ is the weight of substance under standard conditions which will give a direct reading of the specific rotatory power withoutcalculation. In an instrument reading in angular degrees under the usual conditions of $v=100$ and $l=2, w$ is therefore $50 \mathrm{~g}$.

If $a$ is the reading of a saccharimeter with the Ventzke scale, $w=50 \times 0.344=\mathrm{I} 7.20$, and the specific rotatory power of any solution of known concentration of an optically active substance will be $\frac{\mathrm{I} 7.2 a}{w}$. The easiest way of finding the concentration of glucose solutions with sufficient exactness for this work is by the Brix (or Balling) hydrometer, as this instrument is now made of great accuracy.

Brix hydrometers are carried in regular stock of the larger houses dealing in chemical apparatus for brewers and sugar manufacturers, with scales having a range of about five degrees and easily read to 0.05 per cent. Thermometers are attached having corrections for temperature marked on the scale. Concentrations of about ten per cent. are most convenient for polarizing; hence a spindle will be needed reading from five to ten per cent.

The method of determining rotatory powers is as follows: The glucose is diluted to an approximately ten per cent. solution. An exact Brix (or Balling) reading is taken, corrected for standard temperature and the solution polarized in a $200 \mathrm{~mm}$. tube in any saccharimeter with the Ventzke scale. The logarithm of the factor $\frac{17.20}{w}$ corresponding to the Brix reading is then found in the table. Therefore, the calculation which is, $\log [\alpha]_{\mathrm{D}}=\log \left(\frac{\mathrm{I} 7.20}{w}\right)+\log a$, simply requires finding the logarithm of the saccharimeter reading and the number corresponding to the sum of this and the logarithm given in the table. This number is the required specific rotatory power.

1 Obviously a table made on the scheme of the well-known schmitz table for cane. sugar syrups would do away with all calculation. Such a table is, however, rather bulky for insertion here. 
Thus a solution of 7.85 Brix having a reading of $51.7^{\circ}$, Ventzke has the rotatory power of its anhydrous carbohydrates determined as follows :

By the table, the corresponding logarithmic factor is 0.3272 .

$$
\begin{array}{ll}
\log 5 \mathrm{I} .7 & =1.7 \mathrm{I} 35 \\
\text { Factor } & \frac{0.3272}{2.0407}=\log 109.8
\end{array}
$$

which is the required rotatory power.

In this calculation no correction is made for ash, which, as a rule, does not affect the results appreciably.

The errors due to the slight variations in the concentration of the solutions used and changes in the temperature of the laboratory are too small to be taken into consideration in factory work or in general commercial analysis. The method in practice is quite as rapid as the "quotient of purity" determination of canesugar syrups. We suggest that this, or some similar scheme, be uniformly used for expressing the results of all polarimetric investigations of honeys, syrups, and similar indeterminate mixtures of carbohydrates met with in commercial analysis, instead of merely giving the polarizations, or the specific rotatory powers referred to the weights of the sample. The advantages are obvious. Such analytical results would be close approximations to the exact specific rotatory powers of the mixed anhydrous carbohydrates, and would be convenient of interpretation by inspection as being directly comparable on what is for all practical purposes an absolute standard and the one used in all strictly scientific work of the kind.

THE SPEED OF THE HYDROLYSIS OF STARCH BY ACIDS. ${ }^{1}$

The laws of the speed of hydrolysis of the carbohydrates with the exception of that of cane-sugar have been but little studied. Solomon ${ }^{2}$ has collected some data on the action of various acids at boiling temperature. Welhelmy ${ }^{3}$ showed in the case of the catalytic action of hydrochloric acid on cane-sugar that if the

1 We are greatly indebted to Prof. A. A. Noyes, of this department, for valuable aid in calculating the results of this work on speed of hydrolysis.

$2 \mathrm{~J}$. prakt. Chem., (2), 28.

8 Ber. d. chem. Ges., 18, 2211. 
amount of acid and the temperature remained constant the rate of the inversion at any specified moment is proportional to the amount of unchanged sugar present at that moment.

That is, if $A_{0}$ represent the amount of sugar originally present, $x$ the amount of this sugar changed over in any period of time, $t$, and $c$ the reaction-constant, we have $\frac{d x}{d t}=c\left(A_{0}-x\right)$.

The relative values of the constant, $c$, of the various acids in their action on cane-sugar have been determined by several observers, notably Ostwald,' who has compared, by means of their constants, the relative effect of chemically equivalent quantities of a large number of acids, taking the constant of hydrochloric acid as a standard with the arbitrary value of 100 .

Recent work shows that acids act on salicin, ${ }^{2}$ one of the glucosides, in a manner analogous to that of cane-sugar, the speed of hydrolysis of this body by the different acids bearing the same relation to hydrochloric acid.

The observations noted above suggested the possibility that in the hydrolysis of starch the acids would show the same proportional speed of reaction. This is an especially interesting problem because the starch molecule is exceedingly complicated, the molecular weight being undoubtedly very high. Starch hydrolysis, however, must be considered as somewhat different from that of cane-sugar or salicin. While these are easily soluble in cold water, starch is totally insoluble at ordinary room temperature. On the other hand, amylodextrin, the product of decomposition of starch by boiling water, is somewhat soluble in cold water, its solubility increasing with rise of temperature.

As by the customary procedure in determining speed of hydrolysis, it would be necessary to ascertain the exact moment when all the starch has been converted into the soluble form, a point not conveniently determined, we have adopted a method of measurement, based on the following principles:

The conversion products of starch, with the possible exception of those of very high rotatory power, are easily soluble in water, and can be looked upon as mixtures of maltose, dextrose and dextrin.

1 J.prakt. Chem., 1884,401,

2 Noyes and Hall: Ztschr. phys. Chem., 1895, 240. 
The starch first changes to amylodextrin. The hydrolysis then proceeds by successive stages through the so-called maltodextrin, maltose, and dextrose. "Reversion," so-called, may take place to some extent, a small amount of the dextrose forming dextrin-like bodies, "gallisin," " isomaltose," etc., but this point is not considered in this work. The dextrin may therefore be looked upon as the original substance hydrolyzed, and maltose and dextrose as successive products of the reaction.

Further, we have shown that whatever the condition of hydrolysis by acids, the specific rotatory power of any conversion product corresponds to a definite chemical composition, tables for determining which we have constructed.

Thus, for instance, a conversion product of $160^{\circ}$ has been proved to contain 54.8 per cent. dextrin, the remainder being maltose and dextrose.

Hence, the time of taking any sample after the contents of the autoclave has acquired constant temperature, which requires about ten minutes, can be taken as the initial point for determining speed of hydrolysis, and all subsequent samples referred to this, as it is obvious that in any sample we can ascertain the dextrin unacted upon at that stage of the hydrolysis. The same holds true of maltose.

We have to deal with two reactions, the first being the hydrolysis of dextrin to maltose.

If $A_{0}$ is the amount of dextrin at the initial point taken, $A_{0}-x$, the amount remaining at any time, $t$, and $c$ the constant depending on conditions of hydrolysis we get, $\frac{d x}{d t}=c\left(A_{\circ}-x\right)$.

This, on integrating, gives $\log \frac{A_{\circ}}{A-x}=c t$, or $\frac{\mathrm{I}}{t} \log$ $\frac{A_{0}}{A_{0}-x}=c$, which is the general equation of a first-order reaction. The second decomposition is that in which maltose is hydrolyzed to dextrose, and is peculiar in so far as it proceeds simultaneously with that by which the maltose is formed. As a result of the hydrolysis of the dextrin the maltose increases rapidly to a maximum of 44 .I per cent. at a rotation of $129^{\circ}$. 
It then gradually diminishes, while the dextrose percentage always increases.

Consequently, the equation expressing accurately the rate of change in the total amount of maltose present is quite complicated, and we have therefore used an approximate formula, which is sufficiently exact for the work in hand. The formula is derived from the exact differential equation

$$
\frac{d D}{d t}=c_{2} M
$$

which states that the amount of dextrose formed at each moment is proportional to the amount of maltose present by replacing the differential quantities by finite differences, which in applications of the formula must of course be taken small. In the place of $M$ the average amount of maltose present during the interval of time considered is also substituted. That is, if $M_{1}$ and $M_{2}$ are the amounts of maltose present at the time, $t_{1}$ and $t_{2}$, and $D_{1}$ and $D_{2}$ the amounts of dextrose present at these same times, and $c_{2}$ is the reaction constant, we get as a result of the above mentioned substitutions:

$$
D_{2}-D_{1}=c_{2} \frac{M_{1}+M_{2}}{2}\left(t_{2}-t_{2}\right),
$$

or,

$$
\left(\frac{\mathrm{I}}{t_{2}-t_{1}}\right)\left(\frac{D_{2}-D_{1}}{\frac{M_{1}+M_{2}}{2}}\right)=c_{2} .
$$

The results are contained in the following tables:

TABLE E.

SPEED OF HYDROLYSIS OF STARCH.

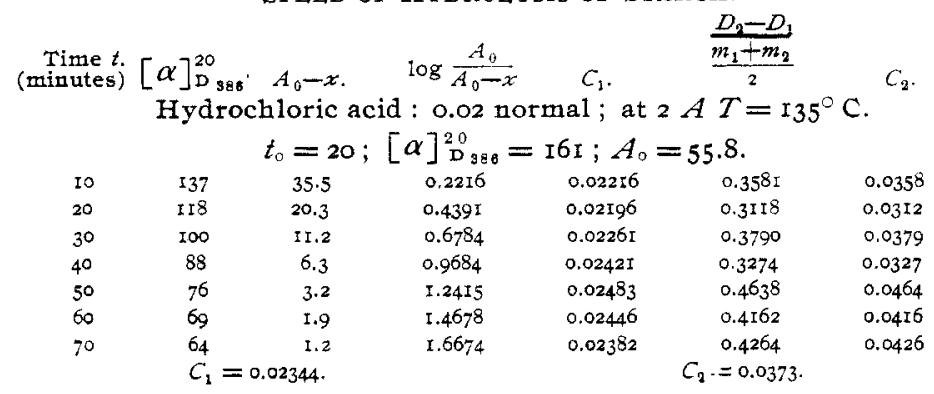


Sulphuric acid : 0.02 normal; at $2 A T=135^{\circ} \mathrm{C}$.

$\begin{array}{rr}10 & 163 \\ 20 & 152 \\ 30 & 140 \\ 40 & 129 \\ 60 & 109 \\ 80 & 90 \\ 100 & 77 \\ 120 & 66\end{array}$

$$
t_{\mathrm{o}}=20 ;[\alpha]_{\mathrm{D} 3 \mathrm{~B} 6}^{20}=177^{\circ} ; A_{\mathrm{o}}=73.5 \text {. }
$$

$\begin{array}{lrllll}163 & 57.9 & 0.1036 & 0.01036 & 0.1954 & 0.0195 \\ 152 & 46.7 & 0.2248 & 0.01124 & 0.1436 & 0.0144 \\ 140 & 36.0 & 0.3100 & 0.01033 & 0.1703 & 0.0170 \\ 129 & 27.5 & 0.4270 & 0.01068 & 0.1678 & 0.0168 \\ 109 & 15.4 & 0.6788 & 0.01131 & 0.3656 & 0.0188 \\ 90 & 7.0 & 1.0212 & 0.01277 & 0.4700 & 0.0235 \\ 77 & 3.4 & 1.3348 & 0.01335 & 0.4809 & 0.0240 \\ 66 & 1.4 & 1.7202 & 0.01434 & 0.6915 & 0.0346 \\ C_{1}=0.0118, & & & C_{2}=0.0211 . & \end{array}$

$C_{2}=0.0211$.

Oxalic acid : 0.04 normal; at $2 A T=135^{\circ} \mathrm{C}$.

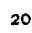

40

60

80

100

120

140

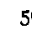

100

150

200

250

300

350

400

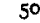

100

150

200

250

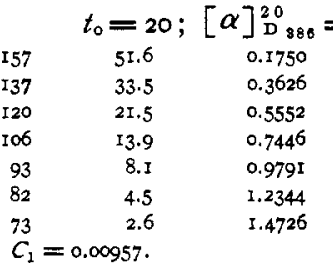

$$
\begin{gathered}
\mathrm{I} 80^{\circ} ; A \\
0.00875 \\
0.00907 \\
0.00925 \\
0.00931 \\
0.00979 \\
0.00029 \\
0.01052
\end{gathered}
$$

\begin{tabular}{|c|c|c|c|c|c|}
\hline \multicolumn{6}{|c|}{$t_{0}=50 ;[\alpha]_{\mathrm{D}}^{20}{ }_{\mathrm{s86}}=\mathrm{I}_{70^{\circ}} ; A_{\circ}=65.5$} \\
\hline 143 & 38.5 & 0.2307 & 0.00461 & 0.3775 & 0.00755 \\
\hline I2I & $22 . I$ & 0.4718 & 0.00472 & 0.3516 & 0.00703 \\
\hline 103 & 12.5 & 0.7193 & 0.00480 & 0.3643 & 0.00729 \\
\hline 86 & 5.6 & 1.0680 & 0.00534 & $0.463^{8}$ & 0.00928 \\
\hline 74 & 2.8 & 1.3690 & 0.00548 & 0.4969 & 0.00994 \\
\hline
\end{tabular}

\begin{tabular}{|c|c|c|c|c|c|c|}
\hline \multicolumn{7}{|c|}{$t_{0}=40 ;[\alpha]_{\mathrm{D} B 8}=183^{\circ} ; A_{0}$} \\
\hline 70 & $15^{8}$ & 52.7 & $0.188_{3}$ & 0.00269 & 0.1358 & 0.00453 \\
\hline 100 & 149 & 43.8 & 0.2686 & 0.00269 & 0.1199 & 0.00400 \\
\hline 140 & 137 & 33.5 & 0.3851 & 0.00275 & 0.1764 & $0.0044 I$ \\
\hline 180 & 126 & 25.5 & $0.503^{6}$ & 0.00280 & 0.1693 & 0.00423 \\
\hline 200 & I2O & 21.5 & 0.5777 & 0.00289 & 0.1028 & 0.00514 \\
\hline 250 & 107 & 14.4 & $0.751^{17}$ & $0 . \infty 0301$ & 0.2539 & 0.00508 \\
\hline
\end{tabular}

Sulphurous acid : 0.02 normal; at $2 A T=135^{\circ} \mathrm{C}$.

\begin{tabular}{rccccc}
\multicolumn{5}{c}{$t_{\mathrm{o}}=50 ;$} & $\alpha \boldsymbol{\alpha}]_{\mathrm{D} 8 \mathrm{888}}^{20}=\mathrm{I8} 7^{\circ} ; A_{0}=87$. \\
179 & 76.0 & 0.0587 & 0.00117 & 0.1254 & $0.0025 \mathrm{I}$ \\
172 & 67.7 & 0.1089 & 0.00109 & 0.0907 & $0.0018 \mathrm{I}$ \\
165 & 60.0 & 0.1613 & 0.00108 & 0.1012 & 0.00202 \\
159 & 53.7 & 0.2095 & 0.00105 & 0.0799 & 0.00159 \\
151 & 45.7 & 0.2796 & 0.00112 & 0.1036 & 0.00207 \\
144 & 39.3 & 0.3451 & 0.00115 & 0.0978 & 0.00196 \\
137 & 33.5 & 0.4145 & 0.00119 & 0.1053 & 0.00211 \\
131 & 29.0 & 0.4773 & 0.00119 & 0.0893 & 0.00179 \\
$C_{1}=0.00113$. & & & $C_{2}=0.00198$. &
\end{tabular}

Acetic acid : 0.5 normal; at $2 A T=135^{\circ} \mathrm{C}$.

Hydrochloric acid : $0.0 \mathrm{~J}$ normal; at I $A T=12 \mathrm{I}^{\circ} \mathrm{C}$. 
Hydrochloric acid : o.oI normal; at $2 A T=135^{\circ} \mathrm{C}$.

$$
t_{0}=20 ;[\alpha]_{\mathrm{D}_{386}^{20}}^{20}=176^{\circ} ; A_{0}=72.3 .
$$

$\begin{array}{rrr}10 & 162 & 56.9 \\ 20 & 148 & 42.9 \\ 40 & 128 & 26.8 \\ 60 & 110 & 16.0 \\ 80 & 93 & 8.1 \\ 100 & 81 & 4.3 \\ 120 & 70 & 2.0 \\ & C_{1}=0.0115 .\end{array}$

$\begin{array}{ll}0.1040 & 0.0104 \\ 0.2256 & 0.0113 \\ 0.4310 & 0.0108 \\ 0.6550 & 0.0109 \\ 0.9506 & 0.0119 \\ 1.2256 & 0.0123 \\ 1.5581 & 0.0130\end{array}$

0.1937
0.1877
0.3015
0.3259
0.4102
0.3830
0.4479
$C_{2}=0.0187$

0.0194 0.0188 0.0151 0.0163 0.0205 0.0182 0.0294

Hydrochloric acid : o.or normal; at $3 A T=\mathrm{I} 45^{\circ} \mathrm{C}$.

$\begin{array}{rrrrrrr}5 & 158 & 52.7 & 0.1233 & 0.0247 & 0.2766 & 0.0553 \\ \text { I0 } & 140 & 36.0 & 0.2888 & 0.0289 & 0.2528 & 0.0506 \\ \text { I5 } & \text { I25 } & 24.8 & 0.4506 & 0.0300 & 0.2351 & 0.0470 \\ 20 & \text { I10 } & 16.0 & 0.6410 & 0.0321 & 0.2756 & 0.0551 \\ 30 & 88 & 6.3 & 1.0458 & 0.0349 & 0.5544 & 0.0554 \\ 40 & 74 & 2.8 & 1.3979 & 0.0350 & 0.5630 & 0.0563 \\ 50 & 65 & 1.3 & 1.7212 & 0.0344 & 0.6349 & 0.0640\end{array}$

Hydrochloric acid : 0.01 normal; at $4 A T=153^{\circ} \mathrm{C}$.

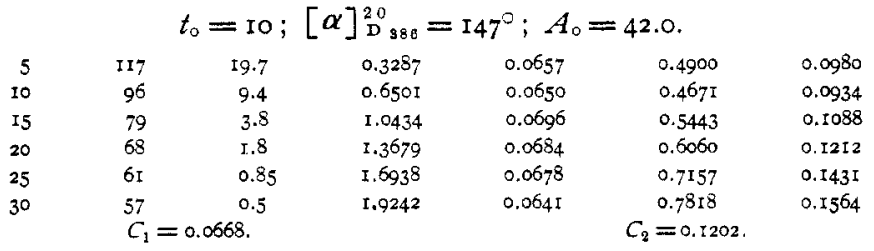

Hydrochloric acid : 0.04 normal; at $3 A T=145^{\circ} \mathrm{C}$.

$\begin{array}{rrrrrrr}3 & 115 & I 8.5 & 0.3831 & 0.1277 & 0.5736 & 0.1912 \\ 5 & 95 & 9.0 & 0.696 I & 0.1392 & 0.454 \mathrm{I} & 0.2270 \\ 7 & 80 & 4.0 & 1.0481 & 0.1497 & 0.4833 & 0.2416 \\ 10 & 66 & 1.4 & I .5042 & 0.1504 & 0.8083 & 0.2694 \\ 13 & 58 & 0.6 & 1.8721 & 0.1440 & 1.0350 & 0.3450 \\ 15 & 66 & 0.4 & 2.0482 & 0.1365 & 0.6285 & 0.3743\end{array}$

Hydrochloric acid : 0.02 normal; at $3 A T=145^{\circ} \mathrm{C}$.

$\begin{array}{rrrrrrr}5 & \text { II6 } & \text { I9.1 } & 0.3515 & 0.0703 & 0.5246 & 0.1029 \\ 10 & 96 & 9.4 & 0.6594 & 0.0659 & 0.4478 & 0.0896 \\ 15 & 80 & 4.0 & 1.0304 & 0.0687 & 0.5075 & 0.1015 \\ 20 & 69 & 1.9 & 1.3537 & 0.0677 & 0.5889 & 0.1178 \\ 25 & 6 \mathrm{I} & 0.85 & 1.703 \mathrm{I} & 0.0681 & 0.7739 & 0.1548 \\ 30 & 56 & 0.45 & 1.9793 & 0.0660 & 1.0800 & 0.2160\end{array}$


HYDROLYSIS OF STARCH BY ACIDS.

Hydrochloric acid : 0.01 normal; at $3 A T=145^{\circ} \mathrm{C}$.

\begin{tabular}{rrrrccc}
\multicolumn{5}{c}{$t_{0}=5 ;$} & {$[\alpha]_{\mathrm{D}_{388}}^{20}=\mathrm{I} 74^{\circ} ; A_{0}=70$.} \\
5 & 158 & 52.7 & 0.1233 & 0.0247 & 0.2766 & 0.0553 \\
10 & 140 & 36.0 & 0.2888 & 0.0289 & 0.2528 & 0.0506 \\
15 & 125 & 24.8 & 0.4506 & 0.0300 & 0.2351 & 0.0470 \\
20 & 110 & 16.0 & 0.6410 & 0.0321 & 0.2756 & 0.0551 \\
30 & 88 & 6.3 & 1.0458 & 0.0349 & 0.5544 & 0.0554 \\
40 & 74 & 2.8 & 1.3974 & 0.0350 & 0.5630 & 0.0563 \\
50 & 65 & 1.3 & 1.7212 & 0.0344 & 0.6349 & 0.0640 \\
& $C_{1}=0.0314$. & & & $C_{2}=0.0548$. &
\end{tabular}

Hydrochloric acid : 0.005 normal; at $3 A T=145^{\circ} \mathrm{C}$.

\begin{tabular}{rrrrrrr}
\multicolumn{6}{c}{$t_{0}=20 ;[\alpha]_{D \text { s8s }}^{20}=17^{\circ} ; A_{0}=67.7}$. \\
20 & 142 & 37.6 & 0.2554 & 0.0128 & 0.4270 & 0.0214 \\
40 & 113 & 17.4 & 0.5901 & 0.0148 & 0.4900 & 0.0245 \\
60 & 91 & 7.3 & 0.9673 & 0.0161 & 0.5226 & 0.0261 \\
80 & 77 & 3.4 & 1.2991 & 0.0162 & 0.5082 & 0.0254 \\
100 & 66 & 1.4 & 1.6845 & 0.0168 & 0.7429 & 0.0371 \\
120 & 59 & 0.7 & 1.9855 & 0.0165 & 0.8172 & 0.0409 \\
& $C_{1}=0.0155$. & & & $C_{2}=0.0279$. &
\end{tabular}

At the head of each table are given data as to the concentration and nature of the acid, the temperature corresponding to the steam pressure given in atmospheres and $[\alpha]_{0}^{20}{ }_{386}^{20}$ at the initial time period $t_{0}$ with the corresponding value of $A_{0}$. Time values are expressed in minutes, and the constants $c_{1}$ for the hydrolysis of dextrin, $c_{2}$ for that of maltose, are calculated according to the formulas given above.

The results show that the constants in general are satisfactory, and that therefore the reaction like the sucrose inversion follows the law of the first order. It will also be seen that the values $c_{1}$ are much more uniform than those of $c_{2}$, which is to be expected since $c_{1}$ is absolute and $c_{2}$ only approximate. Deviations of $c_{1}$ may be fairly ascribed to variations in temperature which, though slight, are significant, owing to the high temperature coefficient of the reaction.

The dextrin values in Table $\mathrm{C}$ are consequently correct within the limits of error of analysis. It will be seen that the values of $c_{2}$ are much more constant in those determinations in which $t$ is larger and the values of $[\alpha]_{D}$ decrease slowly. This was to be expected from the conditions of the approximate formula given above for the decomposition of maltose, these requiring that the amount of substance changed in a period of time must be small. The question of reversion may possibly have some 
influence on the values of $c_{2}$ but as yet we are not prepared to express ourselves definitely on this subject.

The relative effects are shown in the following table: Table I shows the influence on the speed of hydrolysis of various acids at the same temperature, $135^{\circ} \mathrm{C}$.

Table II shows the influence of temperature on the speed of hydrolysis when the same amount of acid is used.

Table III gives the influence of varying amounts of acid.

The mean value of constants are given in column II. Column III gives the relative value of the constants referred to that of ${ }_{1} \frac{1}{0} \sigma 0$ hydrochloric acid at $135^{\circ}$ taken as roo. Column IV gives the velocity constants determined by Ostwald ${ }^{1}$ for canesugar inversion by the same acids at half-normal concentration.

TABLE I.

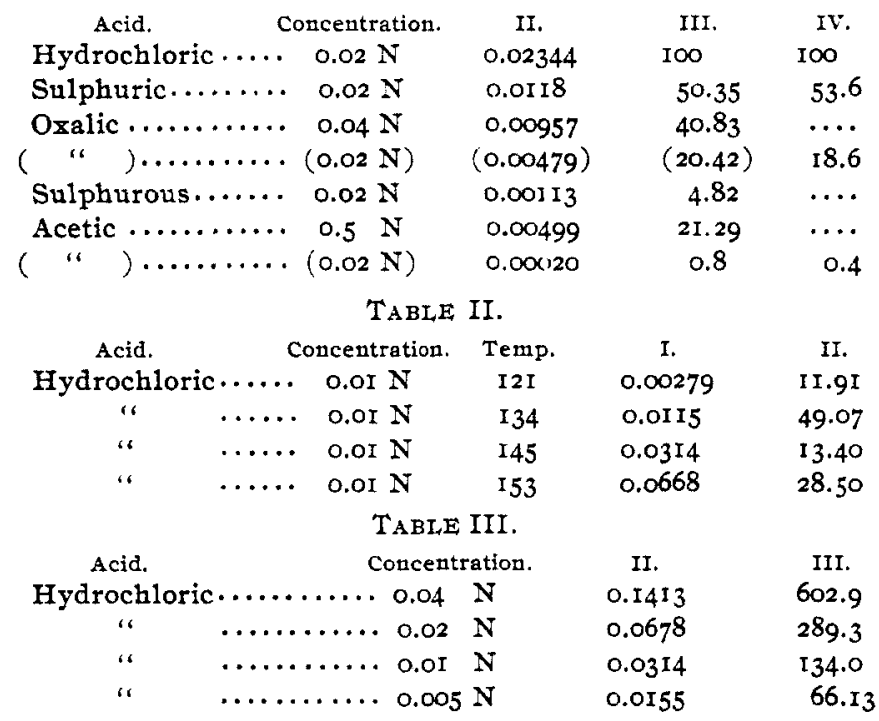

It is seen that the corresponding numbers of columns III and IV agree fairly well. The relative influence of the various acids upon the hydrolysis of starch, sucrose and salicin are therefore nearly identical. It should be noted however that the chemical activity of hydrochloric acid on starch, as in the case of salicin 1 Loc. cit. 
and cane-sugar, increases in a greater ratio than the concentration, while the electrical conductivity increases more slowly. The influence of temperature can be explained graphically by a curve approximating a parabola.

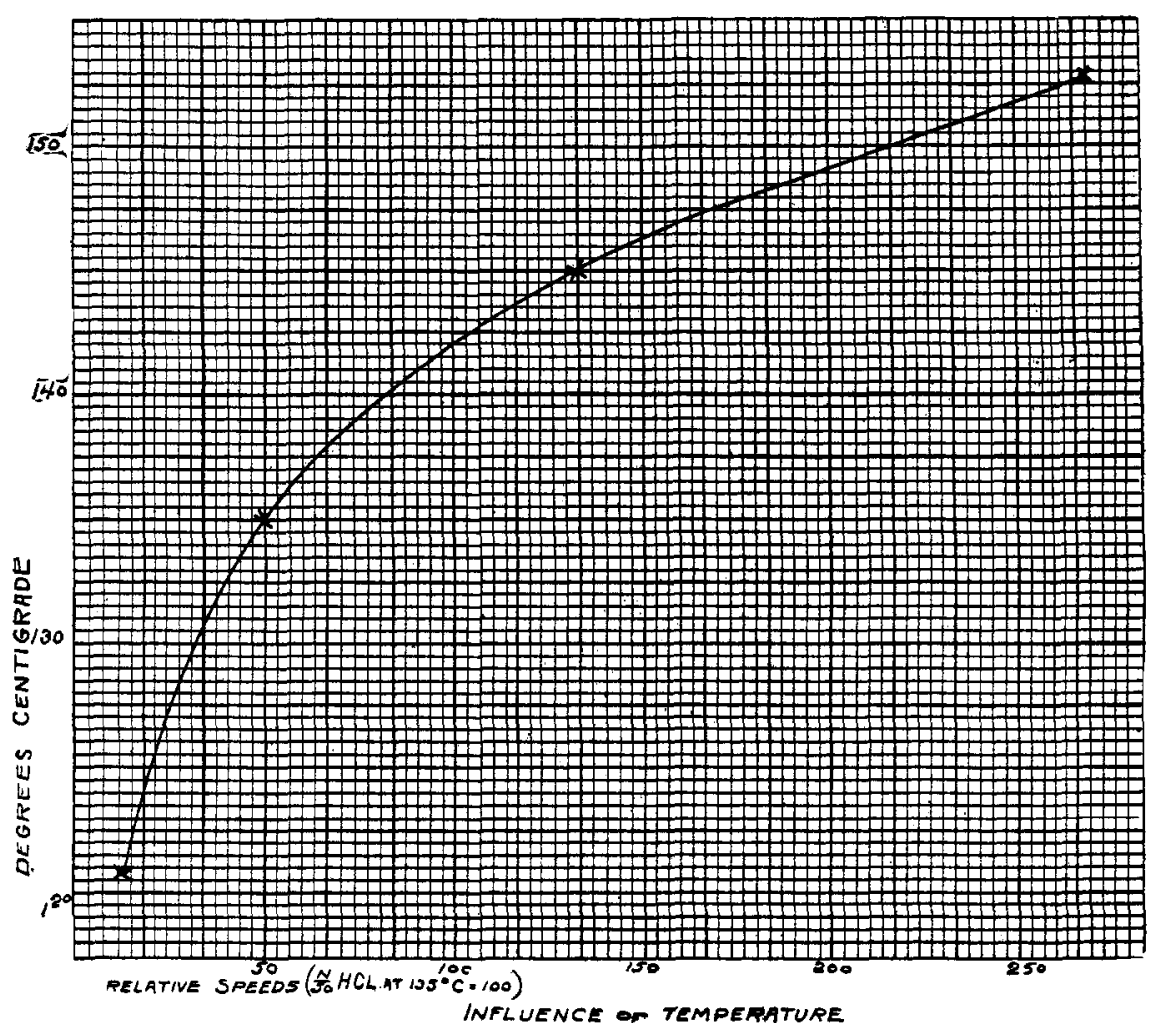

Plate I 
Plate II shows the influence of the various acids.

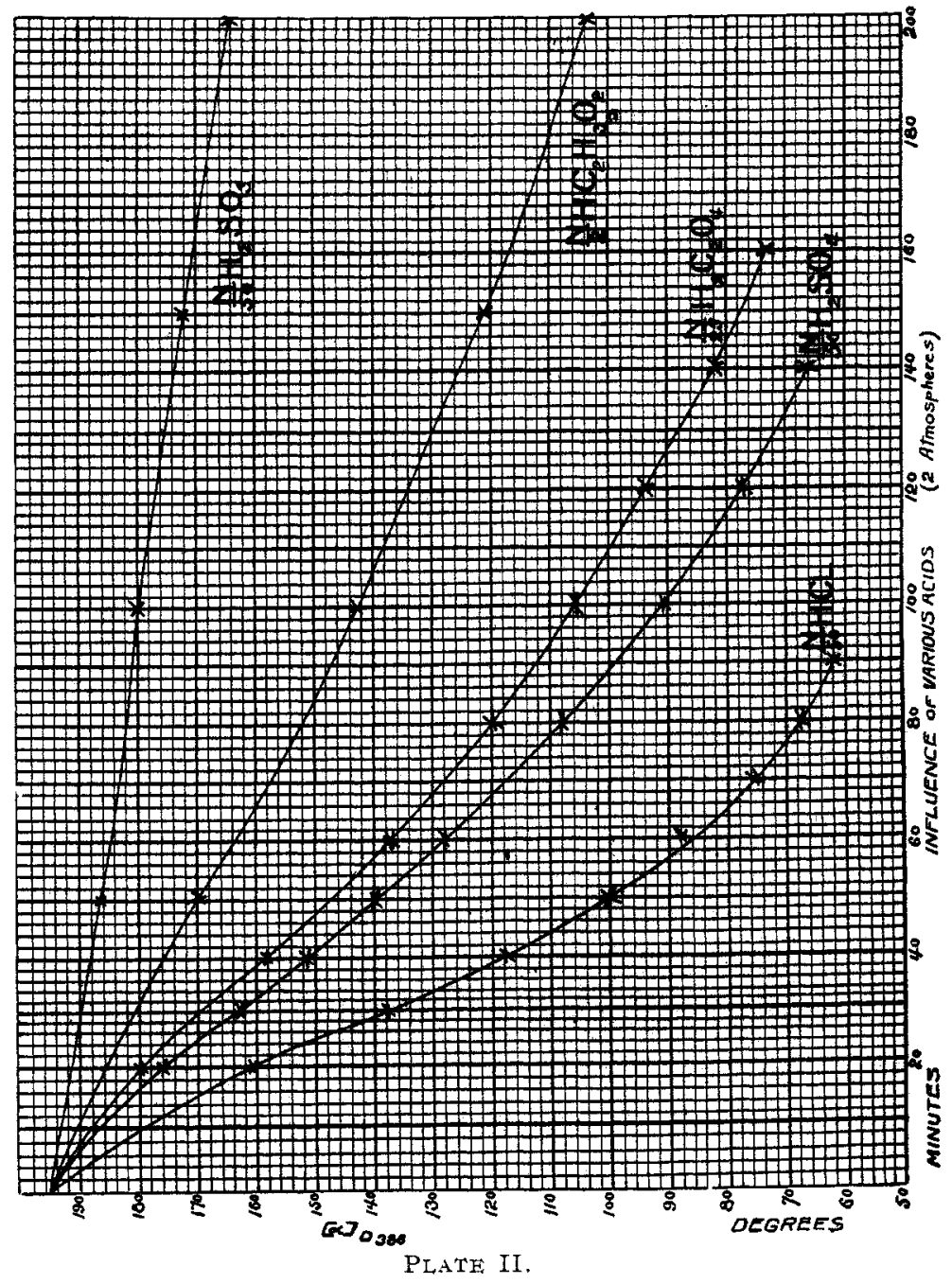


Plate III shows the influence of the concentration, or amount of acid used.

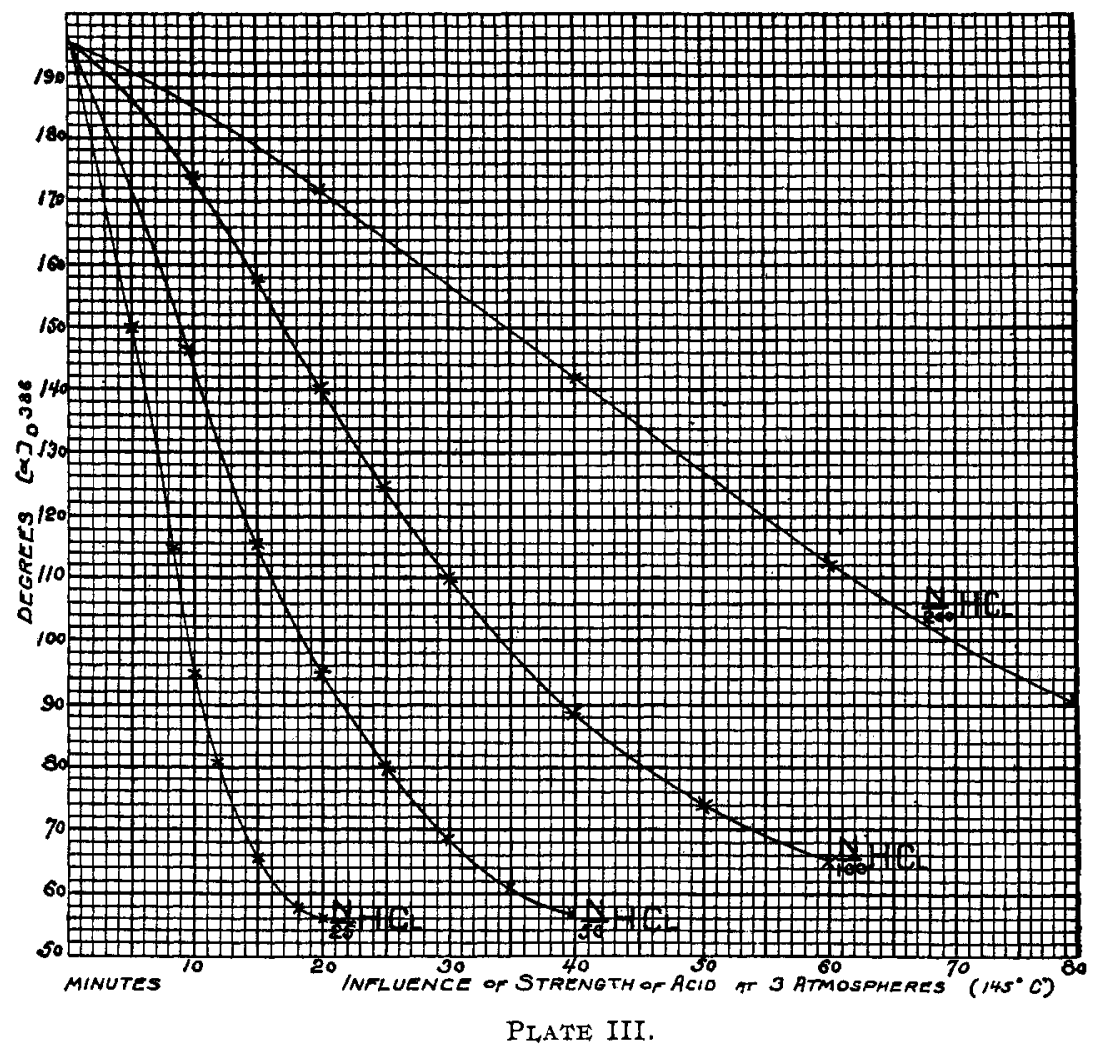


Plate IV shows the relative curves due to temperature.

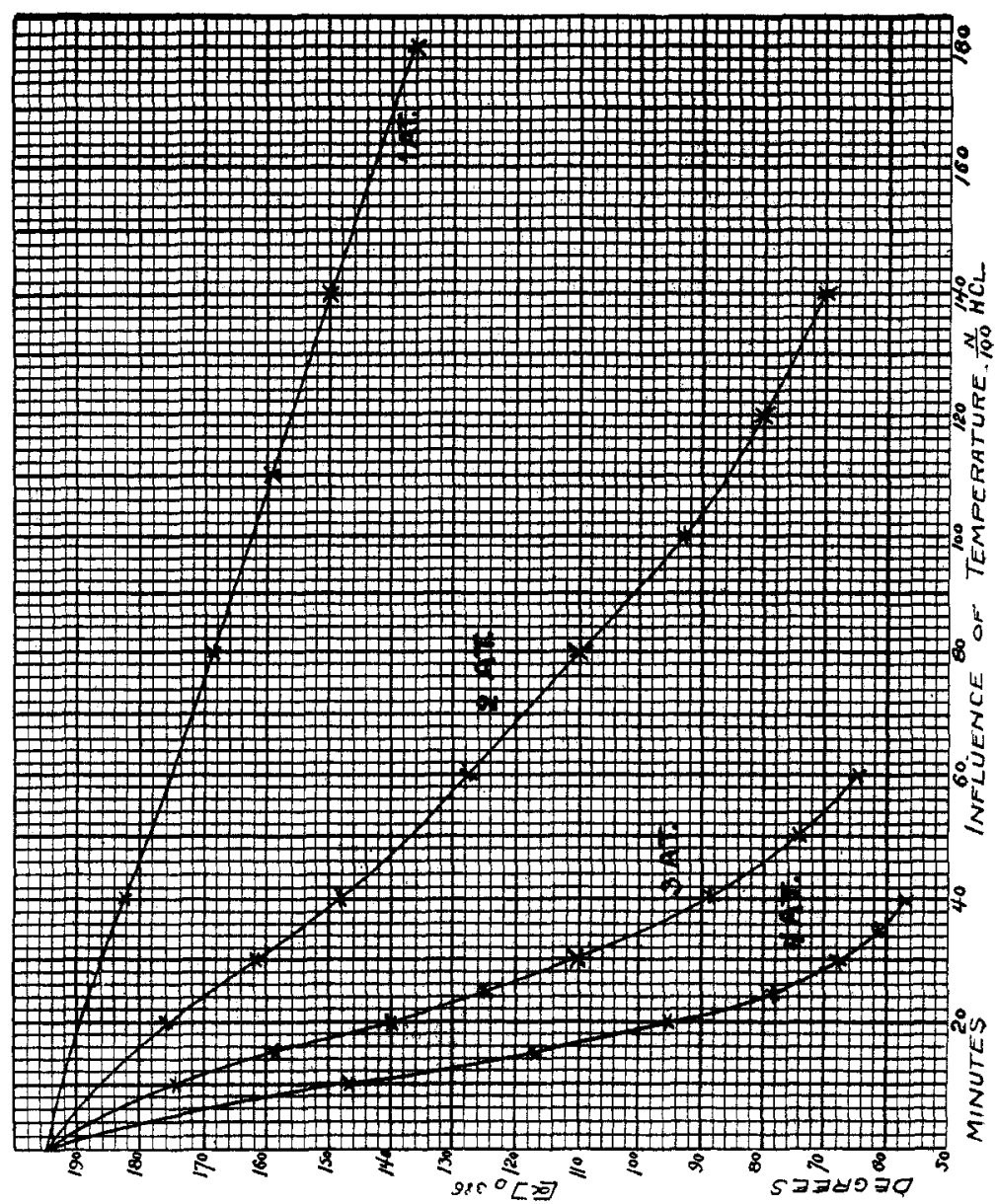

PIATE IV. 